\title{
Local-Scale Valley Wind Retrieval Using an Artificial Neural Network Applied to Routine Weather Observations
}

\author{
FLORIAN DUPUY \\ Laboratoire d'Aérologie, Université de Toulouse, CNRS, UPS, Toulouse, and CEA, DEN, Cadarache, \\ Laboratoire de Modélisation des Transferts dans l'Environnement, Saint-Paul-lès-Durance, France \\ GERT-JAN DUINE \\ Earth Research Institute, University of California, Santa Barbara, Santa Barbara, California \\ PIERRE DURAND \\ Laboratoire d'Aérologie, Université de Toulouse, CNRS, UPS, Toulouse, France \\ THIERRY HedDE AND PIERRE ROUBIN \\ CEA, DEN, Cadarache, Laboratoire de Modélisation des Transferts dans l'Environnement, \\ Saint-Paul-lès-Durance, France \\ ERIC PARDYJAK \\ Department of Mechanical Engineering, University of Utah, Salt Lake City, Utah
}

(Manuscript received 3 July 2018, in final form 14 February 2019)

\begin{abstract}
We hereby present a new method with which to nowcast a thermally driven, downvalley wind using an artificial neural network (ANN) based on remote observations. The method allows the retrieval of wind speed and direction. The ANN was trained and evaluated using a 3-month winter-period dataset of routine weather observations made in and above the valley. The targeted valley winds feature two main directions ( $91 \%$ of the total dataset) that are aligned with the valley axis. They result from downward momentum transport, channeling mechanisms, and thermally driven flows. A selection procedure of the most pertinent ANN input variables, among the routine observations, highlighted three key variables: a potential temperature difference between the top and the bottom of the valley and the two wind components above the valley. These variables are directly related to the mechanisms that generate the valley winds. The performance of the ANN method improves on an earlier-proposed nowcasting method, based solely on a vertical temperature difference, as well as a multilinear regression model. The assessment of the wind speed and direction indicates good performance (i.e., wind speed bias of $-0.28 \mathrm{~m} \mathrm{~s}^{-1}$ and $84 \%$ of calculated directions stray from observations by less than $45^{\circ}$ ). Major sources of error are due to the misrepresentation of cross-valley winds and very light winds. The validated method was then successfully applied to a 1-yr period with a similar performance. Potentially, this method could be used to downscale valley wind characteristics for unresolved valleys in mesoscale simulations.
\end{abstract}

\section{Introduction}

Low-level winds must be well described when studying atmospheric dispersion. Stable conditions are among those that most impact pollution because they tend to

\footnotetext{
Corresponding author: Thierry Hedde, thierry.hedde@ cea.fr
}

trap emissions close to the surface, leading to highpollutant concentrations. Local topography can generate a variety of terrain-induced phenomena near the surface (Chow et al. 2012), including channeling effects which dominate downward momentum transport (Whiteman and Doran 1993). Over complex topography, stable conditions can generate thermally driven flows along slopes and within valleys (Muñoz et al. 2013; Duine et al. 2017; 
Simpson 1994) as well as produce cold pools (Burns and Chemel 2015; Lareau et al. 2013; Price et al. 2011; Clements et al. 2003), which also affect atmospheric dispersion. Numerous experiments have been conducted to study density-driven valley and slope flows and/or cold air pooling, including VTMX (Doran et al. 2002), COLPEX (Price et al. 2011), METCRAX (Whiteman et al. 2008), MATERHORN (Fernando et al. 2015), ASCOT (Clements et al. 1989), and more recently, the Passy project (Sabatier et al. 2018). Most of these and many other complex-terrain studies have been recently reviewed in Rotach et al. (2017).

The Katabatic Winds and Stability over Cadarache for Dispersion of Effluents (KASCADE) experiment (Duine et al. 2017) was conducted in the winter of 2013 in the Cadarache area (southeastern France), in order to investigate the influence of stability on local winds in a small valley. The site features a small valley, where the wind flow is insufficiently monitored by routine meteorological observations to properly calculate the dispersion conditions therein. The currently available meteorological observations can be used, however, to statistically assess winds in the narrow valley. Consequently, Duine et al. (2016, hereafter D16), developed a method for nowcasting the occurrence of downvalley winds that form under stable conditions in the Cadarache valley using observations from the KASCADE campaign. They found that among the permanent measurements available, a valley-scale vertical temperature gradient is a good indicator of the presence of downvalley winds. This method represents the first step toward downscaling local winds; it is, however, restricted to discriminating between the presence or absence of thermally driven winds and is unable to predict the wind speed in the valley. One practical and useful improvement would thus be to nowcast the actual wind speed and direction in the valley using the Cadarache routine observations.

In this paper, we build upon the work of D16 by applying an artificial neural network (ANN) to routine measurements in order to infer the valley winds in the Cadarache valley. Among the nowcasting tools for atmospheric studies, ANNs are increasingly used. Gardner and Dorling (1998) provide an overview of the scope of its utilization in atmospheric studies. An ANN is a statistical tool that reveals the correlation of variables, even if it is unaware of the physical link between the variables. Its principle is to find the best relationship between a set of variables (input variables, always available) so as to calculate an output that is the closest to target variables (observations in our case). For example, Delon et al. (2007) successfully determined nitrogen oxide soil emissions from environmental variables. ANNs have been used for the estimation of an interpolated wind speed field from observations, (Philippopoulos and Deligiorgi 2012) and for predictions on short time scales using a feedforward technique (Cadenas and Rivera 2009; More and Deo 2003), with better performance than more traditional statistical methods. The study of Khosravi et al. (2018) relates the utilization of an ANN to derive the wind direction. In their study, these authors directly derived the wind direction from the ANN. However, we think that the continuous mathematical functions used in ANNs are unable to predict a cyclic variable such as the wind direction, which is prone to jumps at the $0 / 360^{\circ}$ (or $\pm 180^{\circ}$ ) transitions. For this reason, it seems more judicious to estimate the wind direction from the ANN-computed wind components.

The aim of this study is to build an ANN for nowcasting winds in the Cadarache valley, using continuously observed variables as inputs. The ANN enhances the nowcasting work of D16 by computing the actual wind speed and direction at one specific point in the Cadarache valley. The paper is organized as follows. In the second section, the study site and data used are described. The third section is dedicated to the methodology with a presentation of the ANN, its utilization, and how to assess its performance. The results of the ANN are then presented and discussed in the penultimate section of this paper, including a comparison with other techniques. There will be a conclusion in the last section.

\section{Site and data}

\section{a. Site description}

We focus our study on a region of southeastern France, approximately $50 \mathrm{~km}$ north of the Mediterranean Sea in the Alpine foothills that are composed of many small valleys and hills (Fig. 1). The Cadarache valley is oriented in a southeast to northwest direction. It is approximately $6 \mathrm{~km}$ long, $100 \mathrm{~m}$ deep, $1-2 \mathrm{~km}$ wide, and has a mean slope of $1.2^{\circ}$ along its main axis. The winds in the valley have a clearly distinct diurnal pattern with up- and downvalley directions. The Cadarache valley is one of the many tributaries of the Durance valley, which is of a larger scale (in this area, it is oriented north-northeast to south-southwest, is approximately $67 \mathrm{~km}$ long, $200 \mathrm{~m}$ deep, and $5 \mathrm{~km}$ wide, and has a mean slope of $0.2^{\circ}$ along its main axis).

Many meteorological conditions influence the wind patterns in the Cadarache valley. Under stable conditions and clear skies, a clear pattern of thermally driven up- and downvalley flows is found. This behavior was extensively documented during the KASCADE 2013 campaign. Other typical regional meteorological phenomena influencing the local wind patterns are the mistral (Bastin et al. 2005) and precipitation-related 


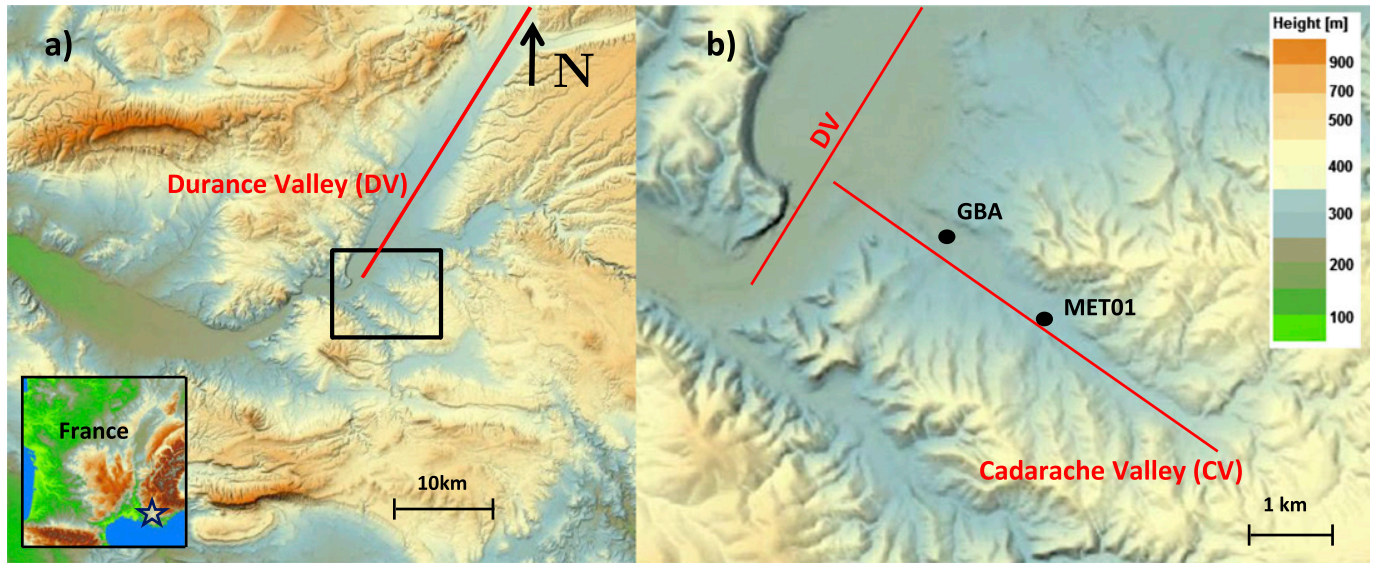

FIG. 1. (a) Topography of the region of Cadarache. (b) Zoomed-in view of the black box in (a). The red lines mark the Durance valley (DV) and the Cadarache valley (CV) axes, and the black dots represent the locations of the meteorological stations MET01 (286 m AGL) and GBA (265 m AGL). (Source: www.geoportail.gouv.fr.)

conditions. The mistral is a northerly regional wind that is often strong and is channeled along the Rhône River valley, spreading to the east and west when it approaches the Mediterranean Sea. A typical mistral situation is shown in Figs. 2c, 2f, and $2 \mathrm{i}$ for the period of
14-16 March 2013. Clear skies are generally associated with mistral conditions, and result in high values of shortwave radiation during the day and large radiative cooling at night. Despite this radiative cooling, the high winds prevent the formation of strong stable stratification.
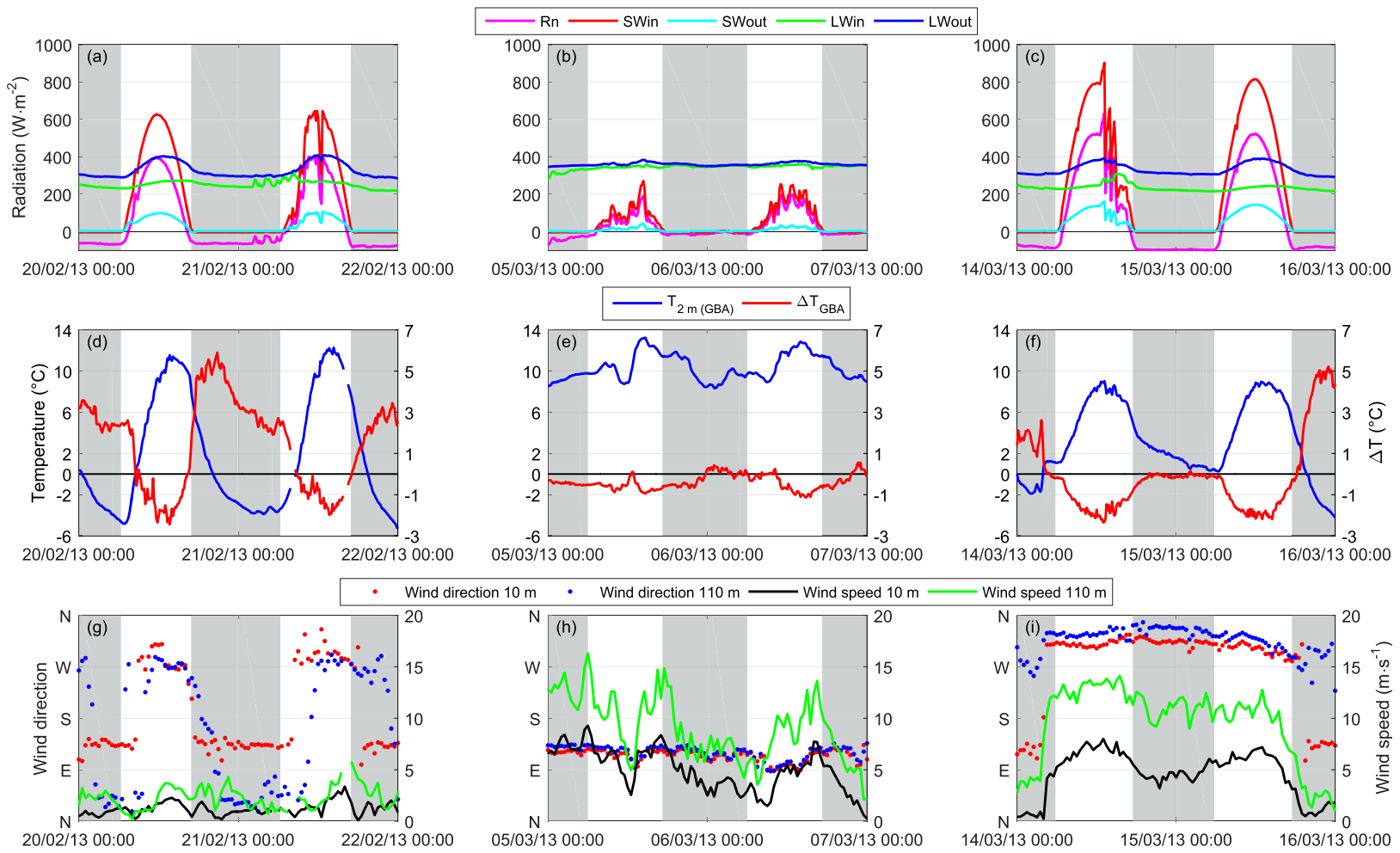

FIG. 2. Meteorological conditions observed in the Cadarache valley during three typical 2-day periods of the KASCADE campaign. (left) Fair-weather conditions, (center) cloudy/rainy conditions, and (right) mistral conditions. (a)-(c) Incoming (in) and outgoing (out) components for shortwave (SW) and longwave (LW) radiation, as well as net radiation $Q_{\text {net }}$ measured at location MET01. (d)-(f) The 2-m temperature and the temperature difference between 2 and $110 \mathrm{~m}$ measured at GBA (Fig. 1). (g)-(i) The wind direction and wind speed measured at 110 (GBA) and $10 \mathrm{~m}$ (MET01). Gray stripes mark nighttime. 
TABLE 1. Summary of observations made in the Cadarache valley: $T$ is temperature, $P$ is pressure, Rh is relative humidity, WS is wind speed, WD is wind direction, and $u, v$, and $w$ correspond to the wind components. The height of measurement is above ground level. See Fig. 1 for stations location.

\begin{tabular}{lclll}
\hline \hline Station & Height $(\mathrm{m})$ & Observed variables & \multicolumn{1}{c}{ Dates } & \multicolumn{1}{c}{ Instrument } \\
\hline MET01 & 2 & WS, WD & 17 Feb 2015-17 Feb 2016 & Campbell Sci. 05103 cup anemometer \\
& 10 & $u, v, w$ & 13 Dec 2012-16 Mar 2013 & Young 81000 sonic anemometer \\
GBA & 2 & $T$ & Continuously & Rotronic PT100 thermometer \\
& & Rh & Continuously & Votronic hygrometer \\
& & $P$ & Continuously & Metek sonic anemometer \\
& 110 & WS, WD & Continuously & Rotronic PT100 thermometer \\
\hline
\end{tabular}

The low-level winds are therefore forced by upper-level winds resulting in northerly winds at all heights. The region is also often subject to southeasterly winds that usually provoke precipitation events (Berthou et al. 2016), especially during the fall. In this case (Figs. 2b,e,h), the upper-level winds force the direction of the winds in the Cadarache valley to be oriented southeasterly. During the remainder of the time, the region is characterized by the frequent occurrence of weak-to-moderate winds and clear skies leading to stable conditions during calm nights and producing thermally driven downvalley winds. These conditions were investigated during the KASCADE experiment (winter of 2013; Duine et al. 2017). The main goal of KASCADE was to observe the evolution of characteristic winds in the Cadarache valley, particularly during stable conditions. During the daytime, winds are mostly westerly to northwesterly in orientation. This is a result of forcing at larger scales (Fig. 2i). After sunset, when the synoptic forcing is sufficiently weak (clear sky and light winds in altitude), stable conditions can occur, and a thermally driven downvalley wind develops in the Cadarache valley (Figs. 2a,d,g). Its thickness is about $50 \mathrm{~m}$ attaining a maximum speed at $25-30 \mathrm{~m}$, as observed during the campaign on tethered-balloon profiles (Duine et al. 2017). The stable situation quickly fades away after sunrise, and is followed by the return of westerly winds. Above the Cadarache downvalley (hereafter $\mathrm{CDV}$ ) wind, and under the same formation conditions, another wind develops between about 100 and $600 \mathrm{~m}$ AGL, the drain current descending the Durance valley with a north-northeast direction (Duine et al. 2017).

\section{b. Observations}

Two observation periods were used in this study. First, a 3-month period during the KASCADE 2013 experiment was used to compare the ANN nowcasting method to that of D16. This experiment was conducted during the winter season, with the highest occurrence of stable conditions. A 1-yr period was then used in order to include a larger range of meteorological conditions and to verify the performance of the ANN method.

\section{1) DATA}

The data used in this study, detailed in Table 1, comprise two main sets, all composed of hourly averaged observations (1899 exploitable samples over 2232 for the KASCADE 2013 experiment and 7991 over 8760 for the 1-yr period):

- The first set of observations are continuous measurements routinely made at the low end of the Cadarache valley (GBA site in Fig. 1). The GBA station is a 110-m tower that measures pressure, relative humidity, and temperature at $2 \mathrm{~m}$, as well as wind speed and direction and temperature at $110 \mathrm{~m}$, a level situated just above the adjacent ridgelines.

- The second set comprises data from temporary stations over limited periods. These were installed inside the Cadarache valley at the MET01 location near the middle of the valley, $1.6 \mathrm{~km}$ upvalley from the GBA station (see Fig. 1). Numerous observations were made here along a vertical profile during the KASCADE experiment between 13 December 2012 and 16 March 2013. Subsequently, MET01 was operated in the same place, instrumented at $2 \mathrm{~m}$ only and providing one entire year of data from 17 February 2015 to 17 February 2016.

\section{2) WIND CHARACTERISTICS}

We examine wind roses at $110 \mathrm{~m}$ during both observation periods (Figs. 3c,d). Both periods exhibit very similar features, with three major wind directions: westerly to northwesterly winds (mix of mistral and typical daytime winds; Figs. 2g,i), north-northeasterly winds aligned with the Durance valley and southeasterly winds generally associated with cloudy/rainy weather (Fig. 2h). The Cadarache valley clearly impacts the wind as nearly all winds observed at $2 \mathrm{~m}$ are aligned with the valley axis (Figs. 3a,b). The large-scale, westerly winds are channeled by the valley and tend to take a northwest (upvalley) direction. The southeasterly winds correspond to a mix of valley-channeled winds (Duine et al. 2017) and rainy weather conditions. No typical 

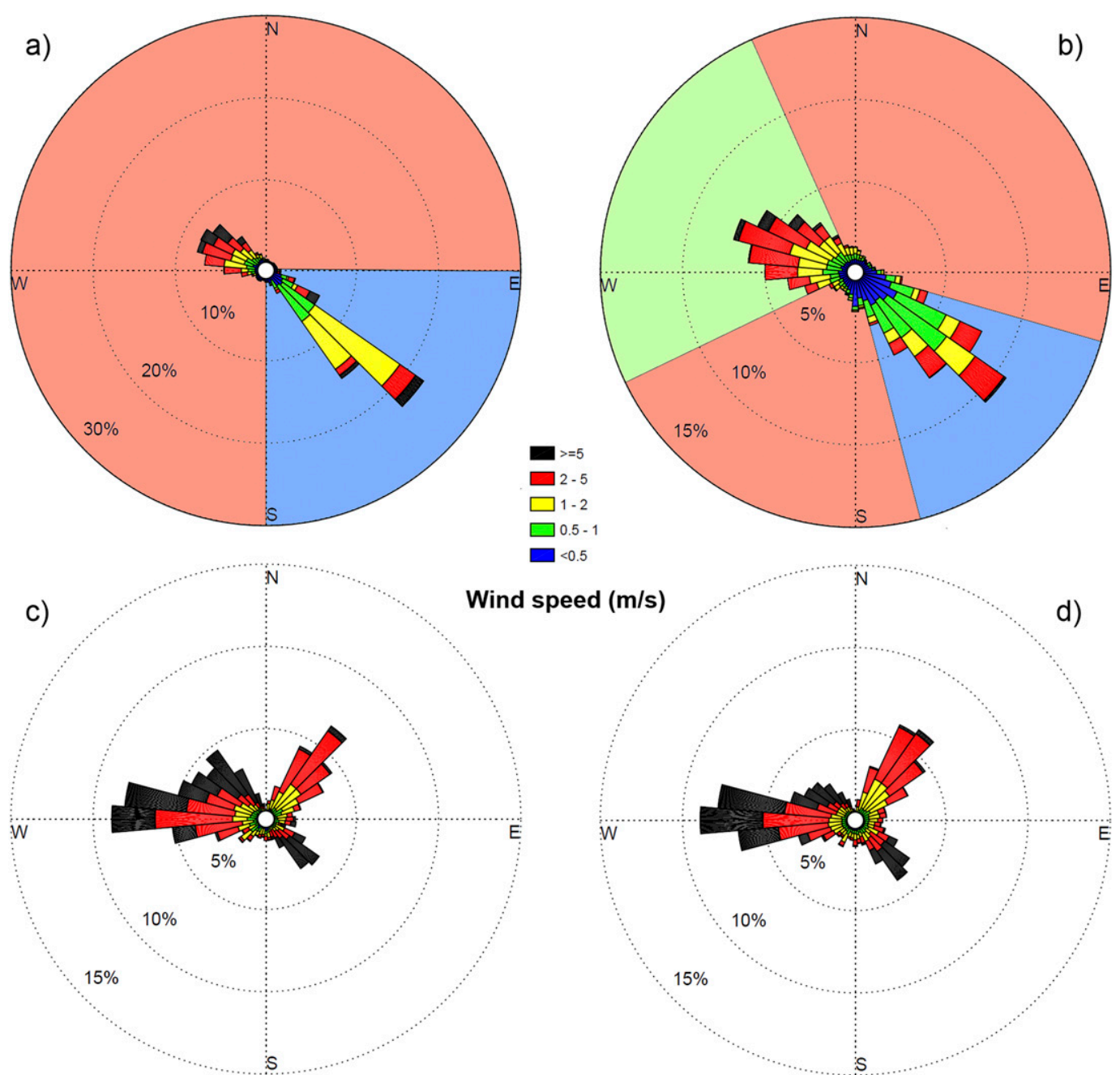

$<0.5$

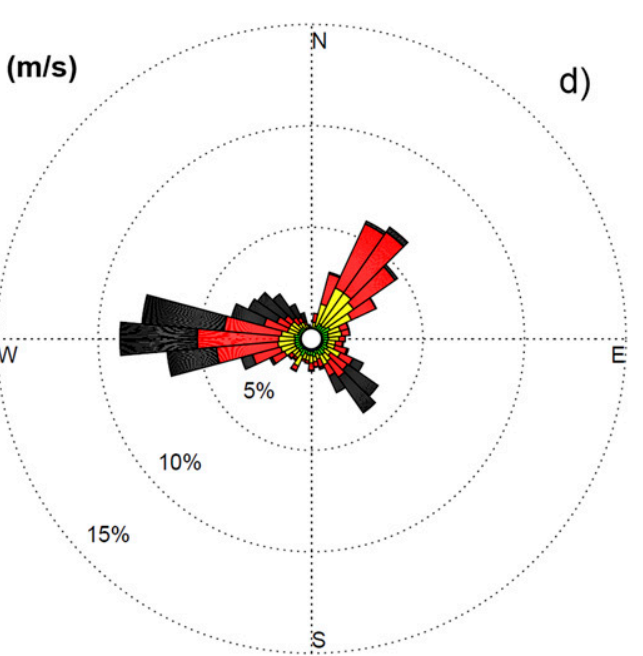

FIG. 3. Wind roses of hourly averaged observations at (a) $10 \mathrm{~m}$ from the KASCADE dataset, (b) $2 \mathrm{~m}$ from the 1 -yr period, (c) $110 \mathrm{~m}$ from the KASCADE dataset, and (d) $110 \mathrm{~m}$ from the $1-\mathrm{yr}$ period. The blue and red (salmon) sectors in (a) correspond to the classification of D16, whereas the three colors in (b) correspond to the classification used in this paper (see section $3 \mathrm{~b}$ ): the blue sector for the CDV winds extends from $105^{\circ}$ to $165^{\circ}$, the green sector for the Cadarache upvalley winds extends from $245^{\circ}$ to $335^{\circ}$, and red sectors include all other directions, corresponding to transverse winds.

meteorological conditions could be associated with cross-valley directions.

The conditions during the KASCADE period repeat themselves often with a high occurrence of $\mathrm{CDV}$ winds $(50 \%$ of total dataset, defined as the blue sector on Fig. 3b) and upvalley winds (41\% of dataset, green sector on Fig. $3 b$ ), and only $9 \%$ of cross-valley winds (red sectors on Fig. $3 b$ ). Over the 1-yr period, the directions at $2 \mathrm{~m}$ are more spread than during the KASCADE period. The channeling of winds is however still clearly visible. The CDV winds represent $38 \%$ of the full dataset; there are $40 \%$ of upvalley winds and $22 \%$ of cross-valley winds. The higher proportion of CDV winds during the KASCADE period (winter) can be explained by the longer nights favorable for these winds.

We demonstrate the local wind characteristics by relating above-valley winds to within-valley winds (Whiteman and Doran 1993) for all winds (Fig. 4a), and we further discriminate between the low-wind conditions $\left(<0.5 \mathrm{~m} \mathrm{~s}^{-1}\right.$; Fig. $4 \mathrm{c})$ and other wind conditions $\left(>0.5 \mathrm{~m} \mathrm{~s}^{-1}\right.$; Fig. $\left.4 \mathrm{~b}\right)$. Two characteristic valley winds appear (Fig. 4b): first, there are two clusters of winds with fairly identical directions at 2 and $100 \mathrm{~m}$. They correspond to westerly-to-northwesterly and southeasterly directions, that is, similar to the orientation of the valley. This is the result of downward momentum transport combined with channeling by the valley walls. It is not easy to distinguish among these two 

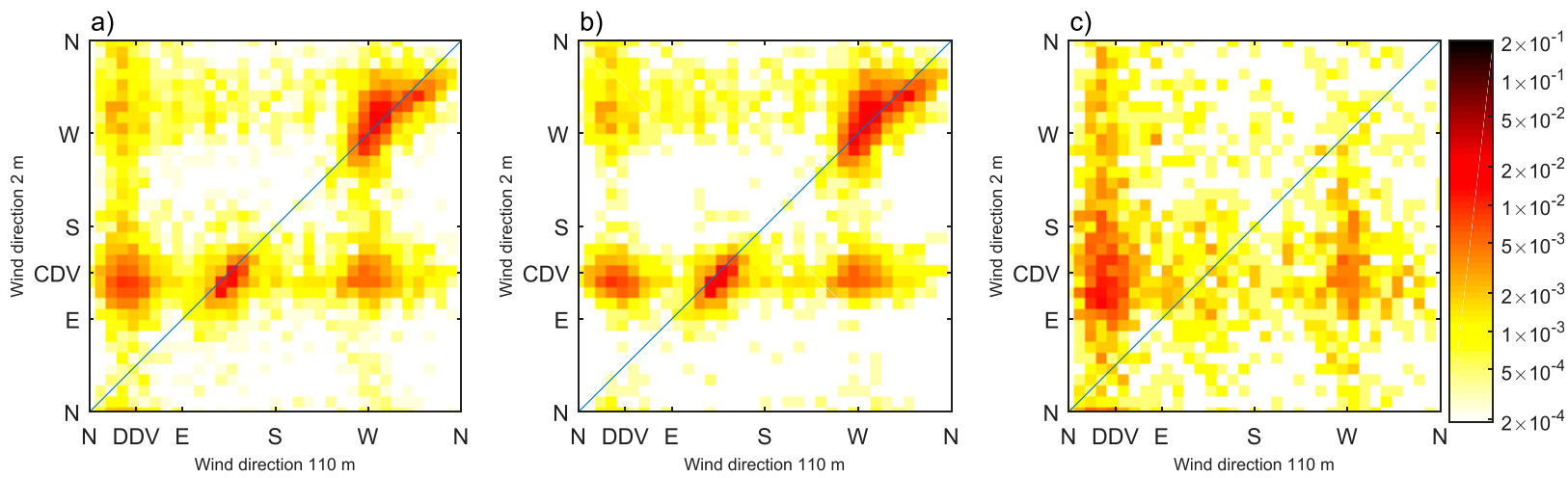

FIG. 4. Probability density showing a comparison of wind directions measured at 110 and $2 \mathrm{~m}$ (a) for the full 1-yr dataset, (b) after removing light winds $\left(<0.5 \mathrm{~m} \mathrm{~s}^{-1}\right.$ at $2 \mathrm{~m}$ ), and (c) for light winds only. CDV represents the Cadarache downvalley direction and DDV the Durance downvalley direction.

mechanisms which one is responsible for the determination of directions in the valley because the above valley winds are almost in alignment with the valley axis. Second, there are 2-m CDV winds, with upper winds blowing either from the west or from the NNE. These CDV winds are thermally driven, during stable stratification periods. They are described in detail by Duine et al. (2017). The upper NNE winds are also thermally driven, but by the Durance valley (Duine et al. 2017). The cluster of 2-m CDV winds associated to upper westerly winds corresponds to the early stage of the CDV winds, in the first hours after sunset, when the Durance downvalley (DDV) wind is not yet established (Duine et al. 2017). Similarly, DDV winds persist several hours after sunrise, whereas CDV winds have already ceased, resulting in the dots of the upper-left-hand corners of Figs. 4a and 4b. For the weak wind conditions (Fig. 4c), downward momentum transport is not observed (as expected), but the other mechanisms described above are still present, even though the scatter is larger because of the higher variability of the wind direction in such conditions.

\section{ANN methodology}

An ANN is a statistical tool, the aim of which is to calculate a mathematical function linking two datasets available over the same period (Yegnanarayana 2009). It is a kind of machine learning algorithm, able to process complex data inputs. The ANN learns to perform tasks by considering examples, generally without being programmed with any task-specific rules. One dataset is composed of known variables [which is the dataset gathering continuous observations in this study described in section $2 b(1)]$ while the other is considered a target to be reproduced [which are temporary observations of the wind in the valley described in section $2 b(1)]$. The ANN starts with a randomly chosen function whose inputs are the known variables. This function is composed of weighted activation functions or neurons, interconnected between each other and arranged in layers.

Each of the two datasets is divided into three subsets: training, validation and test. The first step, applied to the training set, consists of fitting the abovementioned function to produce results as close as possible to the target dataset. This step is iterative and lasts until the performance calculated on the validation set reaches a given limit and no longer improves. The test set is useful for comparing different ANNs because it is the only set that is totally independent from the training of the ANN. The performance of the ANNs is calculated therefore only on the test set. Since ANNs are good interpolators but poor extrapolators (Gardner and Dorling 1998), the dataset used to train the ANN has to be as big and heterogeneous as possible, in order to encompass the widest range of cases that the ANN is expected to treat.

\section{a. ANN configuration}

The ANN used in this study is a multilayer perceptron (MLP) type (Beale et al. 2010). The software is included in the Deep Learning Toolbox of MATLAB. The MLP is frequently used in atmospheric sciences (Gardner and Dorling 1998). Its specific feature is that each neuron of a layer is connected with all neurons of the previous and next layers. It is composed of an input layer, at least one hidden layer and an output layer. Here, the input layer is composed of the training variables and there is a single hidden layer of 10 neurons. To support this choice, we verified that the performances were not improved by adding a second hidden layer, and we evaluated the evolution of the ANN performance when the number of the neurons in the hidden layer varied from 5 to 50 . The output layer (target) is composed of two neurons that are expected to reproduce the horizontal wind components 
at $2 \mathrm{~m}(u$ and $v)$. These components are used to calculate wind speed and direction. The activation function is a hyperbolic tangent function because it offers more favorable results than other tested functions (e.g., logsigmoid or linear functions), the Levenberg-Marquardt algorithm was chosen as training algorithm because it is described in the MATLAB toolbox user's guide as the fastest training algorithm and performances are very similar for all tested algorithms (LevenbergMarquardt, BFGS Quasi-Newton, and Scaled Conjugate Gradient). The pseudorandom generation of the initial weights is also tested by training several ANNs with different seeds. The seed producing the best results is selected.

The dataset was split into $60 \%$ training data, $10 \%$ validation data, and the remaining $30 \%$ was used as the test subset. With respect to the default values in MATLAB, we increased by $10 \%$ the amount of the validation and test sets $(40 \%$ instead of $30 \%)$ in order to avoid overtraining, which can occur when too much of the dataset is used for training. All input variables were normalized between -1 and +1 in order to avoid weight discrepancy problems, which occur when the order of magnitude of variables differs.

\section{b. ANN performance evaluation}

The ANN outputs are evaluated by comparing wind speed and direction with the observations (i.e., targets). The performance of the wind-direction nowcasts was measured by using (i) the DACC (Direction Accuracy; Santos-Alamillos et al. 2013) metric, which represents the proportion of horizontal winds which do not depart by more than $45^{\circ}$ from observations, and (ii) the PC (Proportion Correct) metric which indicates the proportion of values correctly classified in different wind sectors defined from the observed wind rose to represent the main wind regimes. Two forms of PC are used. PC2, used by D16, considers two wind sectors: the southeast quarter for downvalley winds for the first class and all other directions for the second class. It is the only criterion used in D16's nowcasting method. PC4 considers four classes: a first class for light winds (lower than $0.5 \mathrm{~m} \mathrm{~s}^{-1}$ ) that have no well-defined direction, then a class of CDV winds, a class of upvalley winds, and a class of cross valley winds. The last three classes correspond to the blue, green, and red regions, respectively, in Fig. 3b. The three classes of PC4 representing a sector are chosen based on the wind rose observed at $2 \mathrm{~m}$ across the 1-yr period; these classes allow the discrimination of all valley winds whereas the PC2 metric is mostly adapted to assess the representation of the downvalley winds. The performance of the wind speed nowcast is assessed using the correlation coefficient, bias, and mean absolute error (MAE) computed between observed values and ANN output.

All these metrics were calculated on the test dataset. To assess their sensitivity to the test dataset, a bootstrap method was applied using 10000 subsamples taken from the test set. Each subsample was created using a random sampling with a replacement from the original test set. The function produced by the ANN was then applied to each subsample, producing 10000 output datasets. The performance metrics were calculated for each output dataset to build a distribution for each metric. This distribution was used to calculate the mean value for each metric with a confidence interval (at $90 \%$ ) defined as the interval between the 5th and 95th percentiles.

\section{c. Choice of input variables}

Dreyfus et al. (2002) have developed a method for selecting the most pertinent variables to use as input of an ANN. This is performed in two phases:

1) The correlation coefficients between each possible pair of variables are calculated, and when the values are high (absolute value higher than 0.9), the two corresponding parameters are considered redundant and one of them is removed under physical and statistical considerations.

2) In the second selection stage, the input dataset is constructed by iteration (stepwise forward regression; Dreyfus et al. 2002). A reference ANN is launched with all variables still available as inputs after the first stage (which we call $\mathrm{ANN}_{\text {ref }}$ ). For the first iteration, "elementary" ANNs are defined, each one using a single input variable taken from among the input variables of $\mathrm{ANN}_{\text {ref. }}$. The performance metrics of these elementary ANNs are compared to each other so that the importance of each input variable can be determined. The input variable set is thus progressively constructed by adding one more input variable to the selected variables at each iteration. The performance of the ANNs is compared to the reference one at the end of each iteration. This process is continued until improvements in the performance metrics are no longer significant.

\section{Results and discussion}

We first assess the ability of the ANN method to nowcast winds in the Cadarache valley by using the 3-month KASCADE dataset. The performance is compared to the temperature threshold method of D16, and to a simple multilinear regression. The improved nowcasting associated with the ANN method compared to 
TABLE 2. Summary of the D16, ANN, and MLR performance metrics. Mean absolute error (MAE): PC2 for the two D16 wind direction classes and PC4 for the four classes (see Fig. 2b). $\mathrm{ANN}_{\mathrm{K}}$ and $\mathrm{ANN}_{\mathrm{K}-\mathrm{LW}}$ show the results for the 3-month KASCADE period with and without periods with wind speeds $<0.5 \mathrm{~m} \mathrm{~s}^{-1}$, respectively, $\mathrm{ANN}_{\mathrm{K}-\mathrm{DC}}$ shows the results for the same period using only two variables relative to the diurnal cycle (hours relative to the closest sunset and sunrise), and MLR $_{\mathrm{K}}$ shows the results for the same 3-month KASCADE period for the multilinear regression. For each ANN, the mean value of the metrics is on the upper line and the $90 \%$ confidence interval is on the lower line.

\begin{tabular}{|c|c|c|c|c|c|c|c|c|}
\hline \multirow[b]{2}{*}{ Case } & \multicolumn{3}{|c|}{ Direction indicators } & \multicolumn{3}{|c|}{ Correlation } & \multicolumn{2}{|c|}{ Speed $\left(\mathrm{m} \mathrm{s}^{-1}\right)$} \\
\hline & DACC & PC2 & $\mathrm{PC} 4$ & Speed & $u$ & $v$ & Bias & MAE \\
\hline D16 & - & 0.78 & - & - & - & - & - & - \\
\hline $\mathrm{ANN}_{\mathrm{K}}$ & $\begin{array}{c}0.84 \\
{[0.81,0.87]}\end{array}$ & $\begin{array}{c}0.89 \\
{[0.86,0.92]}\end{array}$ & $\begin{array}{c}0.84 \\
{[0.81,0.87]}\end{array}$ & $\begin{array}{c}0.93 \\
{[0.92,0.95]}\end{array}$ & $\begin{array}{c}0.95 \\
{[0.94,0.97]}\end{array}$ & $\begin{array}{c}0.93 \\
{[0.92,0.95]}\end{array}$ & $\begin{array}{c}-0.28 \\
{[-0.33,-0.23]}\end{array}$ & $\begin{array}{c}0.54 \\
{[0.50,0.57]}\end{array}$ \\
\hline $\mathrm{ANN}_{\mathrm{K}-\mathrm{LW}}$ & $\begin{array}{c}0.92 \\
{[0.89,0.94]}\end{array}$ & $\begin{array}{c}0.95 \\
{[0.93,0.97]}\end{array}$ & $\begin{array}{c}0.86 \\
{[0.83,0.89]}\end{array}$ & $\begin{array}{c}0.94 \\
{[0.92,0.95]}\end{array}$ & $\begin{array}{c}0.97 \\
{[0.95,0.98]}\end{array}$ & $\begin{array}{c}0.95 \\
{[0.93,0.96]}\end{array}$ & $\begin{array}{c}-0.22 \\
{[-0.27,-0.16]}\end{array}$ & $\begin{array}{c}0.52 \\
{[0.48,0.56]}\end{array}$ \\
\hline $\mathrm{ANN}_{\mathrm{K}-\mathrm{DC}}$ & $\begin{array}{c}0.55 \\
{[0.52,0.59]}\end{array}$ & $\begin{array}{c}0.64 \\
{[0.60,0.68]}\end{array}$ & $\begin{array}{c}0.57 \\
{[0.53,0.61]}\end{array}$ & $\begin{array}{c}0.49 \\
{[0.42,0.56]}\end{array}$ & $\begin{array}{c}0.64 \\
{[0.58,0.69]}\end{array}$ & $\begin{array}{c}0.53 \\
{[0.47,0.58]}\end{array}$ & $\begin{array}{c}-1.02 \\
{[-1.14,-0.91]}\end{array}$ & $\begin{array}{c}1.34 \\
{[1.24,1.44]}\end{array}$ \\
\hline $\operatorname{MLR}_{K}$ & 0.77 & 0.84 & 0.75 & 0.90 & 0.92 & 0.91 & -0.26 & 0.66 \\
\hline
\end{tabular}

the temperature threshold method is then assessed and discussed.

\section{a. Selection of variables}

Routine observations from the permanent 110-mtower weather station (GBA in Table 1) are used as inputs for the ANN. They include observations at $110 \mathrm{~m}$ (the temperature $T_{110 \mathrm{~m}}$ and wind), and at $2 \mathrm{~m}$ (the atmospheric pressure $P_{2 \mathrm{~m}}$, temperature $T_{2 \mathrm{~m}}$, and relative humidity $\mathrm{Rh}_{2 \mathrm{~m}}$ ). Moreover, the specific humidity calculated at $2 \mathrm{~m} Q_{2 \mathrm{~m}}$ and the potential temperature difference between 110 and $2 \mathrm{~m} \Delta \theta$ are also used as additional input variables. The wind speed $U_{110 \mathrm{~m}}$, as well as the northern and eastern components, $u_{110 \mathrm{~m}}$ and $v_{110 \mathrm{~m}}$, respectively, are retained. It is preferable to use the components as an input variable rather than the wind direction because the cyclic nature of the latter is difficult to handle with the ANN. Altogether, they constitute nine variables which are tested during the first step of selection $\left(\Delta \theta, u_{110 \mathrm{~m}}, v_{110 \mathrm{~m}}, U_{110 \mathrm{~m}}, P_{2 \mathrm{~m}}, Q_{2 \mathrm{~m}}, T_{110 \mathrm{~m}}, T_{2 \mathrm{~m}}\right.$, and $\mathrm{Rh}_{2 \mathrm{~m}}$ ). Three groups of three variables are potentially redundant $\left(\Delta \theta, T_{110 \mathrm{~m}}\right.$, and $T_{2 \mathrm{~m}}$ for temperature observations; $u_{110 \mathrm{~m}}, v_{110 \mathrm{~m}}$, and $U_{110 \mathrm{~m}}$ for wind observations; and $Q_{2 \mathrm{~m}}, T_{2 \mathrm{~m}}$, and $\mathrm{Rh}_{2 \mathrm{~m}}$ for 2-m observations). This redundancy is removed through the selection step which defines the most relevant variables as those that yield the best performance of the ANN. The most pertinent variables are defined as being those which allow the ANN to reach the best results.

Concerning temperatures, a high correlation coefficient (0.92) was found between $T_{2 \mathrm{~m}}$ and $T_{110 \mathrm{~m}}$. The correlation coefficients between $T_{2 \mathrm{~m}}$ and $\Delta \theta(-0.66)$ and between $T_{110 \mathrm{~m}}$ and $\Delta \theta(-0.32)$ clearly indicate the need to retain $T_{110 \mathrm{~m}}$ and $\Delta \theta$ rather than $T_{2 \mathrm{~m}}$ and $\Delta \theta$; thus $T_{2 \mathrm{~m}}$ is removed. This reflects that the variation of $\Delta \theta$ in the diurnal cycle is controlled by that of $T_{2 \mathrm{~m}}$ rather than that of $T_{110 \mathrm{~m}}$. The negative correlations are explained by the fact that $\Delta \theta$, which reflects the stratification close to the surface, is negative for daytime, convective conditions and positive for nighttime stable stratifications, whereas the air temperature (either at $2 \mathrm{~m}$ or at $100 \mathrm{~m}$ ) is higher during the day than during the night. Concerning the other variables, they are all retained because their correlations are weaker (the maxima obtained are 0.70 between $Q_{2 \mathrm{~m}}$ and $T_{110 \mathrm{~m}}$, and 0.68 between $Q_{2 \mathrm{~m}}$ and $T_{2 \mathrm{~m}}$ ). Finally, eight variables remained after the first step of selection: $\Delta \theta$, $u_{110 \mathrm{~m}}, v_{110 \mathrm{~m}}, U_{110 \mathrm{~m}}, P_{2 \mathrm{~m}}, Q_{2 \mathrm{~m}}, T_{110 \mathrm{~m}}$, and $\mathrm{Rh}_{2 \mathrm{~m}}$.

The second phase of the input variable selection process starts with the construction of a reference ANN $\left(\mathrm{ANN}_{\mathrm{ref}}\right)$, in which the remaining eight variables are used as input. The final input dataset is then constructed following the procedure described in section $3 \mathrm{c}$. This process produced three input variables $\left(\Delta \theta, u_{110 \mathrm{~m}}\right.$, and $\left.v_{110 \mathrm{~m}}\right)$ for the ANN, which resulted in 10-m wind nowcast without a significant loss of performance. This optimized ANN, which uses observations from the KASCADE dataset, is called $\mathrm{ANN}_{\mathrm{K}}$ and its performance is presented in Table 2.

\section{b. Results and comparison with other statistical methods}

To assess the ability of the ANN method to nowcast winds in the Cadarache valley, we compared its performance to two other statistical methods: the D16 method and a multilinear regression (MLR).

Here, we will briefly review the D16 nowcasting method as a baseline for comparison to the proposed ANN method. Based on routine measurements from the 110-m GBA tower, D16 found a criterion for the diagnosis of the existence of a thermally driven downvalley wind in the Cadarache valley. They developed this method using data from the 3-month KASCADE 

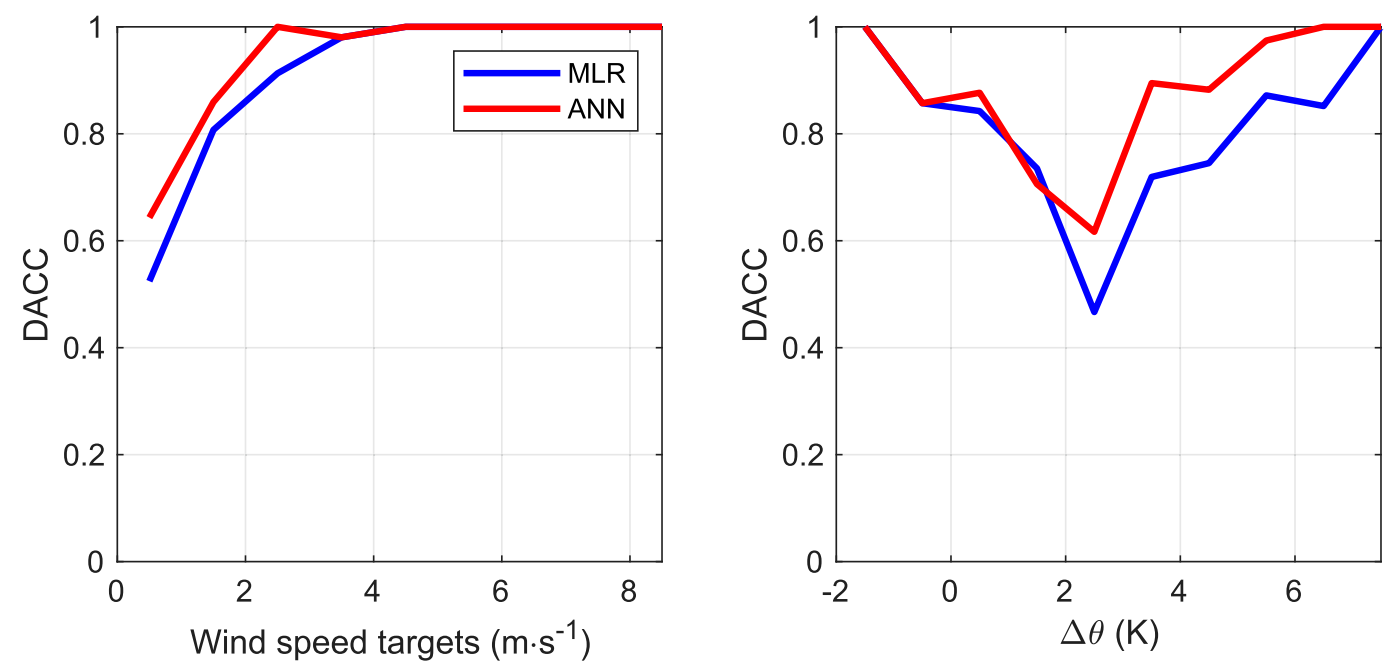

FIG. 5. Comparison of DACC values from the $\mathrm{ANN}_{\mathrm{K}}$ (red) and MLR (blue) as a function of (left) the observed wind speed and (right) the observed potential temperature difference between 110 and $2 \mathrm{~m}$. The plots are relative to the 3-month KASCADE period.

period. Under the D16 criterion, if a potential temperature difference between 110 and $2 \mathrm{~m}$ exceeds $2.6 \mathrm{~K}$, then a downvalley flow exists. The technique performs well, with $90 \%$ of accurate predictions (PC2 of 0.90 , see details in section $3 b$ ). The method has been developed to highlight thermally driven, southeasterly winds in the Cadarache valley. These winds are not only thermally driven, however, as they can also result from a synoptic forcing [section $2 \mathrm{~b}(2)]$. To avoid the confusion between these two mechanisms, D16 removed those winds which were synoptically forced. If all winds are included, the overall performance is somewhat reduced, with a PC2 of 0.78 . The threshold for the temperature difference was also slightly modified, with a value of $2.5 \mathrm{~K}$ instead of $2.6 \mathrm{~K}$.

The MLR is among the simplest methods to rely input and output parameters, hence it is natural to wonder what benefits arise due to ANNs with respect to MLR. To be comparable with the ANN, the MLR was operated with the same variables $\left(\Delta \theta, u_{110 \mathrm{~m}}\right.$, and $\left.v_{110 \mathrm{~m}}\right)$ and the fitting equation was computed on the training and validation sets of the ANN. The MLR equations obtained for the $u$ and $v$ components are

$$
\begin{aligned}
& u_{\mathrm{MLR}}=0.296-0.279 \Delta \theta+0.278 u_{110 \mathrm{~m}}-0.275 v_{110 \mathrm{~m}}, \\
& v_{\mathrm{MLR}}=0.057+0.166 \Delta \theta-0.095 u_{110 \mathrm{~m}}+0.297 v_{110 \mathrm{~m}} .
\end{aligned}
$$

The D16 method only discriminates wind directions such as CDV or non-CDV according to the value of the vertical potential temperature difference on the $110-\mathrm{m}$ GBA mast. As mentioned above, the ANN method goes beyond the D16 method's ability to determine the existence of downvalley winds and computes the two wind components. The performance of the three methods for the KASCADE dataset are summarized in Table 2. The $90 \%$ confidence intervals on the ANN metrics correspond to the bootstrap results as explained in section $3 \mathrm{~b}$.

The $\mathrm{ANN}_{\mathrm{K}}$ achieves a PC2 of 0.89 , with a confidence interval between 0.86 and 0.92 . This is significantly better than that achieved by D16 and by the MLR. The comparison of the ANN and MLR methods with the other metrics demonstrates the superiority of the ANN compared with the MLR. To determine for which conditions the differences between the two methods are the highest, we analyzed how their respective performances evolve when the wind or the stratification varies. This is presented in Fig. 5 for the DACC metrics. The differences are higher for light winds $\left(<3 \mathrm{~m} \mathrm{~s}^{-1}\right)$ and very stable conditions $(\Delta \theta>2 \mathrm{~K})$. For high winds, and close-to-neutral or unstable stratifications, the two methods achieve comparable performances, which can be related to a higher coupling between the winds above and at the bottom of the valley, due to forced channeling (high winds) or turbulent mixing (unstable conditions).

The final comparison between observed and ANN nowcasted wind direction and speed is presented in Fig. 6. The ANN reproduces the wind-direction pattern well, with two dominant winds (southeasterly and northwesterly winds), as well as the wind speed. These performances are quantified using several metrics indicated by $\mathrm{ANN}_{\mathrm{K}}$ in Table 2. The direction-related metrics all have success rates higher than $80 \%(\mathrm{PC} 2=0.89 ; \mathrm{PC} 4=0.84$; DAAC $=0.84)$. The correlation coefficients for the two wind components as well as wind speed reach values 

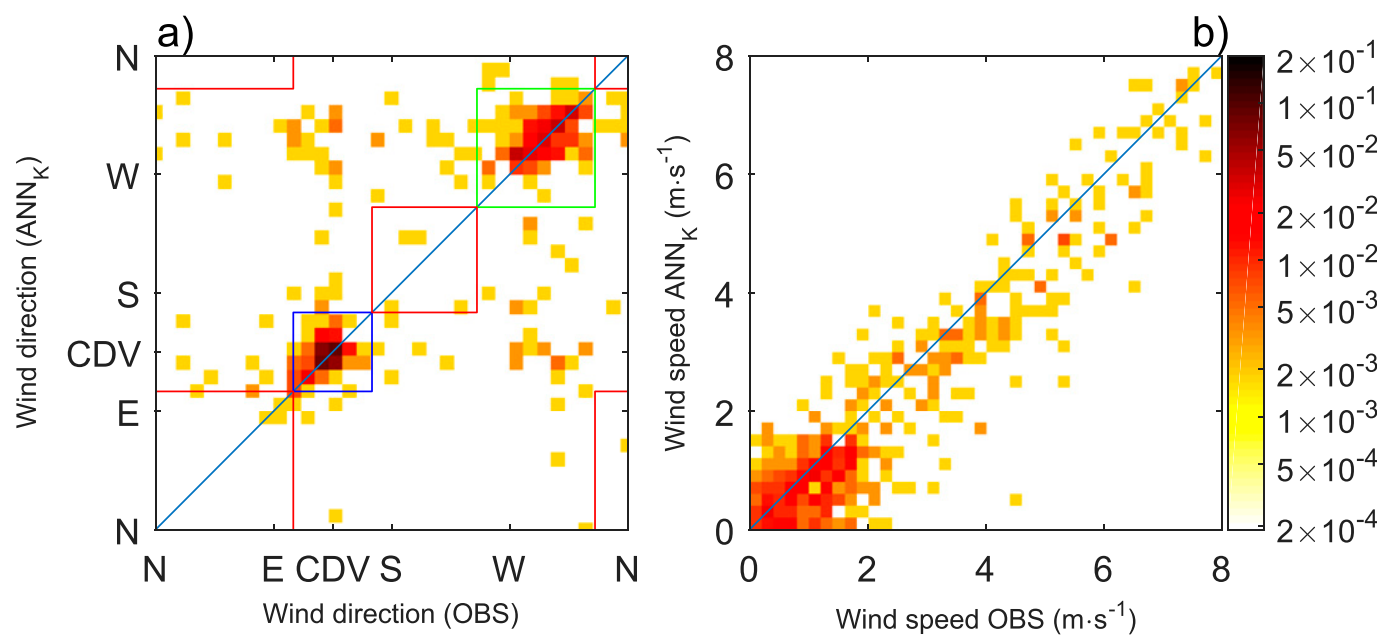

FIG. 6. Comparison of the 10-m (a) wind direction and (b) wind speed observed and nowcasted, represented by a probability density (color scale). Densities are calculated for wind direction bins of $10^{\circ}$ and wind speed bins of $0.2 \mathrm{~m} \mathrm{~s}^{-1}$. The red, green, and blue rectangles in (a) correspond to the three wind direction categories shown in Fig. 3.

between 0.93 and 0.95 , and the bias on wind speed is as low as $-0.28 \mathrm{~m} \mathrm{~s}^{-1}$ for a mean speed of $2.11 \mathrm{~m} \mathrm{~s}^{-1}$. For these reasons, we conclude that a method using ANNs yields very good performance and allows a more reliable operational nowcasting than D16's $\Delta \theta$ criterion or a MLR technique.

\section{c. Relative effect of ANN input parameters}

Using only three variables $\left(u_{110 \mathrm{~m}}, \boldsymbol{v}_{110 \mathrm{~m}}\right.$, and $\left.\Delta \theta\right)$ as ANN inputs, the ANN is capable of calculating the $10-\mathrm{m}$ wind speed and direction at one point in the Cadarache valley. One may, however, observe that the impact of each variable on the ANN result differs.

The ANN calculates the two wind components at $10 \mathrm{~m}$, requiring that the wind components at $110 \mathrm{~m}$ be used. The wind at these levels has different patterns. At $10 \mathrm{~m}$, it is strongly impacted by the local topography in the Cadarache valley, while the wind at $110 \mathrm{~m}$ reflects the influence of a larger area. Despite these differences, the correlation coefficients for the wind components at 10 and $110 \mathrm{~m}$ reach 0.80 and 0.81 for the $u$ and $v$ components, respectively, which reveals the importance of these variables for the calculation.

Duine et al. (2017) have revealed the high occurrence of CDV winds and they have demonstrated that they are induced by topography under stable conditions. The use of $\Delta \theta$, which is related to atmospheric stability, enables the ANN to improve the nowcasting of the CDV winds. As shown by D16, $\Delta \theta$ is strongly connected to the thermally driven downvalley wind. Increasing stable stratification is closely linked to the frequency of occurrence of downvalley winds as shown in Fig. 7b.
The selection of variables shows that the $10-\mathrm{m}$ wind can be reproduced by taking into account the abovevalley winds (by using the wind components at $110 \mathrm{~m}$ ) and the generation of downvalley winds under stable conditions (using the $\Delta \theta$ ). This is consistent with the results shown in section $2 b(2)$.

\section{d. Effect of the diurnal cycle}

In the boundary layer, most meteorological variables have a strong diurnal pattern. We should therefore ask whether a large part of the ANN output was a simple reproduction of this cycle. To highlight information carried from the diurnal cycle to the wind prediction, we made an additional ANN (called $\mathrm{ANN}_{\mathrm{K}-\mathrm{DC}}$ ) with only two variables as input, namely, the times relative to the closest sunrise and sunset. The scores of this ANN are presented in Table 2 (row " $\mathrm{ANN}_{\mathrm{K}-\mathrm{DC}}$ "). The information contained in the diurnal cycle is considerable. It is far from being sufficient however to provide a satisfactory performance (i.e., at a level comparable to the performance obtained with the three meteorological parameters used as input for the ANN). The metrics are much lower than those of the $\mathrm{ANN}_{\mathrm{K}}$ showing that the diurnal cycle does impact the ANN calculation but does not carry as much information as the three variables used by the $\mathrm{ANN}_{\mathrm{K}}$.

\section{e. Limitation for light winds}

Although the ANN is a good tool for nowcasting of lowlevel winds in the Cadarache valley, there are, however, a few observations for which the wind directions are poorly reproduced by the $\mathrm{ANN}_{\mathrm{K}}$ (see Fig. 6a the dots outside the colored boxes). Given the very high correlation between 
a)

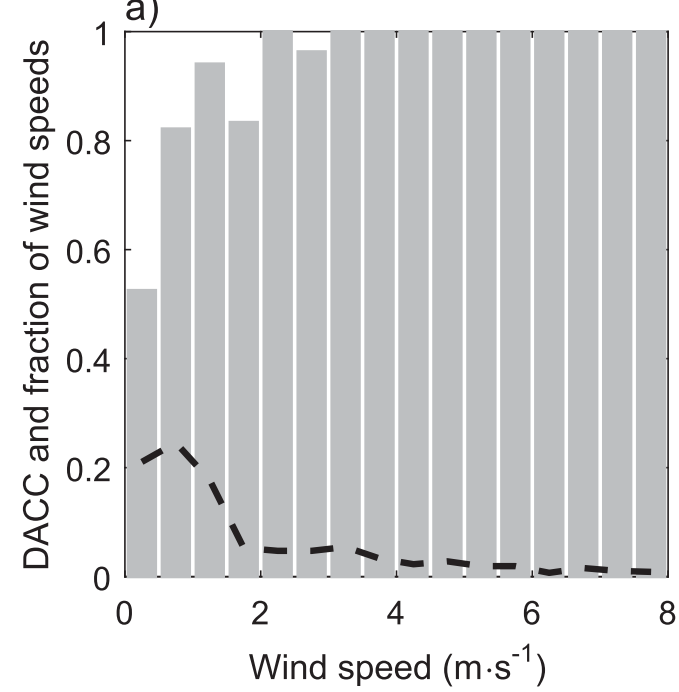

b)

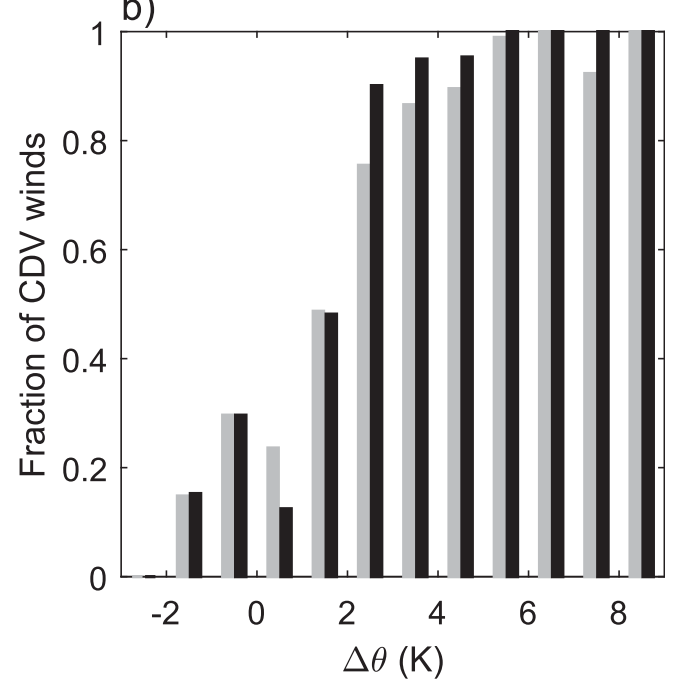

FIG. 7. (a) DACC values as a function of the ANN-calculated wind speed (gray bars) and the proportion of data in each wind speed bin (black dashed line). (b) Proportion of observed (gray) and $\mathrm{ANN}_{\mathrm{K}}$ nowcasted (black) 10-m CDV winds as a function of the observed potential temperature difference between 110 and $2 \mathrm{~m}$. The plots are relative to the 3-month KASCADE period.

observed and $\mathrm{ANN}_{\mathrm{K}}$-computed wind components $(0.95$ and 0.93 for $u$ and $v$, respectively), these defects can be attributed to very weak winds for which the directions are highly sensitive to small variations of the components values. This is due to the indirect calculation of the wind direction (from wind components), which is impossible to compute as a cyclic function through the ANN. A small error made in one component for lower winds produces a larger error in the wind direction than for stronger winds. Wind directions for winds with a speed lower than $0.5 \mathrm{~m} \mathrm{~s}^{-1}$ were found to be badly reproduced by the ANN, with a DACC of 0.53 (Fig. 7a). The $\mathrm{ANN}_{\mathrm{K}}$ performance indices were thus recalculated after wind speeds (from the ANN outputs) lower than $0.5 \mathrm{~m} \mathrm{~s}^{-1}$ were removed (note that the removal of light winds beforehand a learning step on the basis of target winds is impossible without introducing a bias). The corresponding row in Table $2\left(\mathrm{ANN}_{\mathrm{K}-\mathrm{LW}}\right)$ clearly shows the improvement of direction metrics DACC and PC2 above those of $\mathrm{ANN}_{\mathrm{K}}$. PC4 is only slightly improved because one of the four classes is dedicated to light winds, independent of their directions. Neither the correlation coefficients, nor the mean absolute error of the wind speed are significantly modified. The negative bias on the wind speed is reduced, showing that light winds were underestimated by $\mathrm{ANN}_{\mathrm{K}}$.

\section{f. Performance of the ANN over a 1-yr period}

To encompass a wider range of meteorological conditions, the ANN method is assessed over a 1-yr period. As indicated above, this period lasts from 17 February 2015 to 17 February 2016. To check if the synoptic meteorological conditions were not unusual during this period, and therefore if our results could be regarded as valid whatever the year considered, we checked the year-toyear variability of the wind observed at $110 \mathrm{~m}$, which is representative of a scale larger than that of the valley. For the period between early 2010 and the end of 2017 (corresponding to the dataset at our disposal), the eight yearly wind roses appear to be very similar, and resemble that presented in Fig. 3d, with the same three main wind directions. The only year-to-year difference lies in the occurrence of the strongest SE winds, associated to bad weather episodes.

This new ANN, called $\mathrm{ANN}_{1 \mathrm{yr}}$, has exactly the same structure as $\mathrm{ANN}_{\mathrm{K}}$. The selection step revealed that the same three variables are the most pertinent ones $\left(\Delta \theta, u_{110 \mathrm{~m}}\right.$, and $\left.v_{110 \mathrm{~m}}\right)$. Its performances are presented in Table 3 (rows " $\mathrm{ANN}_{1 \mathrm{yr}}$ " and " $\mathrm{ANN}_{1 \mathrm{yr}-\mathrm{LW}}$ "). These performances are slightly worse than those computed over the 3-month period $\left(\mathrm{ANN}_{\mathrm{K}}\right.$ and $\left.\mathrm{ANN}_{\mathrm{K} \text {-LW }}\right)$, but they are not noticeably different. The visual comparison of wind speed and direction (Fig. 8) highlights the same limitations as those with the KASCADE dataset. Specifically, the representation of the light winds and crossvalley winds remains a challenge.

\section{g. Length of the dataset}

In the previous section, we demonstrated the efficiency of the ANN method when applied to a dataset involving a larger diversity of input conditions. The increase of size from the 3 -month to the 1 -yr period 
TABLE 3. As in Table 2, but for the 1-yr period. $\mathrm{ANN}_{1 \mathrm{yr}}$ and $\mathrm{ANN}_{1 \mathrm{yr}-\mathrm{LW}}$ show the results with and without wind speeds lower than $0.5 \mathrm{~m} \mathrm{~s}^{-1}$, respectively.

\begin{tabular}{|c|c|c|c|c|c|c|c|c|}
\hline \multirow[b]{2}{*}{ Case } & \multicolumn{3}{|c|}{ Direction indicators } & \multicolumn{3}{|c|}{ Correlation } & \multicolumn{2}{|c|}{ Speed $\left(\mathrm{m} \mathrm{s}^{-1}\right)$} \\
\hline & $\mathrm{DACC}$ & $\mathrm{PC} 2$ & PC4 & Speed & $u$ & $v$ & Bias & MAE \\
\hline $\mathrm{ANN}_{1 \mathrm{yr}}$ & $\begin{array}{c}0.81 \\
{[0.77,0.84]}\end{array}$ & $\begin{array}{c}0.88 \\
{[0.85,0.91]}\end{array}$ & $\begin{array}{c}0.83 \\
{[0.80,0.86]}\end{array}$ & $\begin{array}{c}0.92 \\
{[0.90,0.94]}\end{array}$ & $\begin{array}{c}0.94 \\
{[0.93,0.96]}\end{array}$ & $\begin{array}{c}0.86 \\
{[0.83,0.90]}\end{array}$ & $\begin{array}{c}-0.24 \\
{[-0.29,-0.19]}\end{array}$ & $\begin{array}{c}0.52 \\
{[0.48,0.55]}\end{array}$ \\
\hline $\mathrm{ANN}_{1 \mathrm{yr}-\mathrm{LW}}$ & $\begin{array}{c}0.90 \\
{[0.87,0.93]}\end{array}$ & $\begin{array}{c}0.96 \\
{[0.93,0.98]}\end{array}$ & $\begin{array}{c}0.83 \\
{[0.80,0.87]}\end{array}$ & $\begin{array}{c}0.91 \\
{[0.88,0.93]}\end{array}$ & $\begin{array}{c}0.95 \\
{[0.93,0.96]}\end{array}$ & $\begin{array}{c}0.88 \\
{[0.85,0.91]}\end{array}$ & $\begin{array}{c}-0.18 \\
{[-0.25,-0.12]}\end{array}$ & $\begin{array}{c}0.55 \\
{[0.51,0.60]}\end{array}$ \\
\hline
\end{tabular}

does not however improve the performance. Therefore, we assessed the impact of the length of the dataset on the ANN performance, with shorter datasets. These tests were conducted on the 3-month KASCADE dataset.

A total of 550 subsamples of the input dataset were created, ranging from $100 \%$ (1899 samples) to $5 \%$ (95 samples) of the entire dataset. For each reduced size, 50 random subsamples were created (the random draw guarantees selected data from all seasons and hours, avoiding seasonal or diurnal cycle bias). This allowed us to investigate the effect of a sample size, particularly for the smallest datasets for which two different random samples can generate datasets without any common values. For each size, the overall performance of the ANN is characterized by the median value and the 5 th and 95 th percentiles computed over the 50 index values.
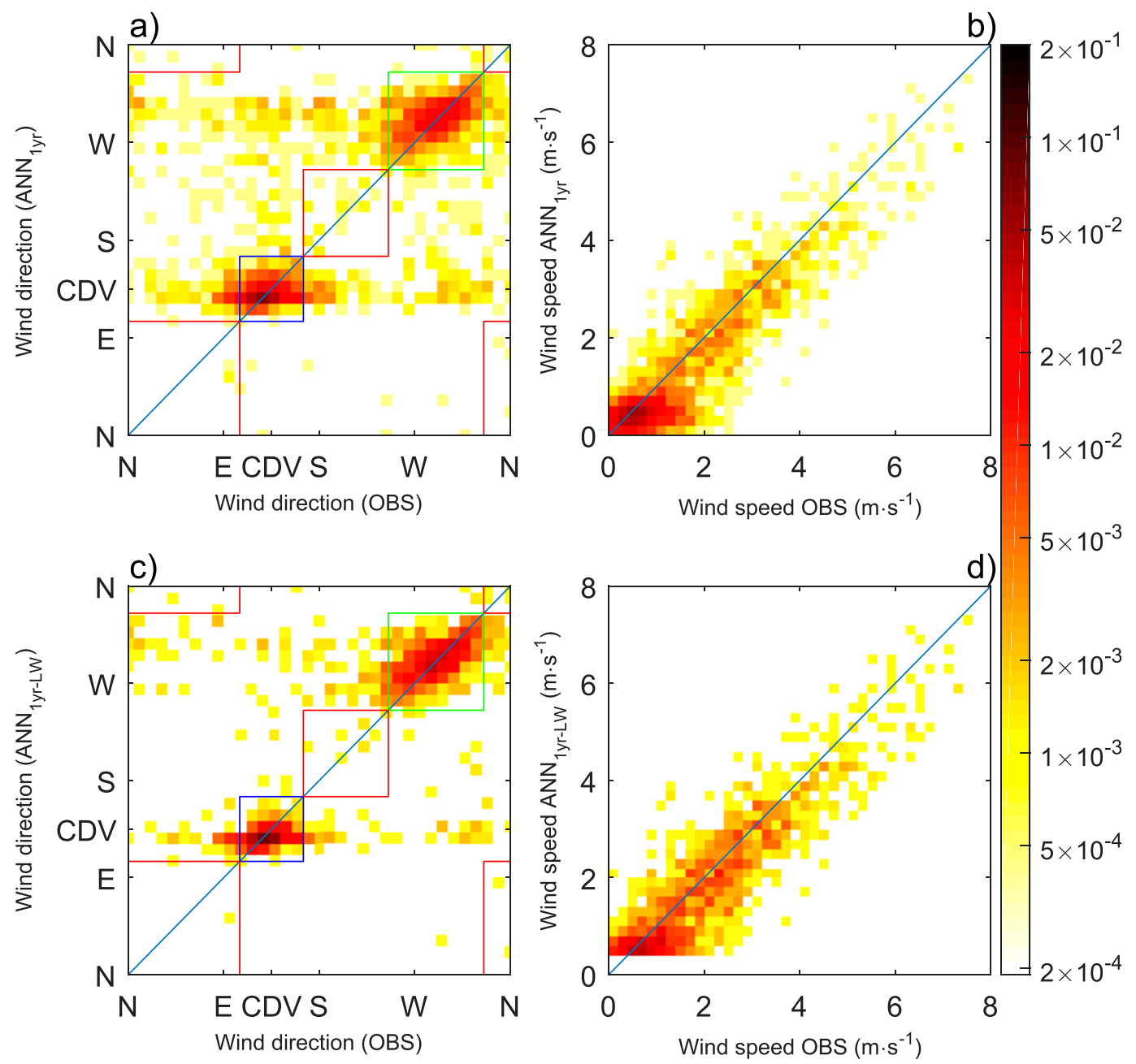

FIG. 8. As in Fig. 6, but for the (a),(b) $\mathrm{ANN}_{1 \mathrm{yr}}$ and (c),(d) $\mathrm{ANN}_{1 \mathrm{yr}-\mathrm{LW}}$ outputs. 

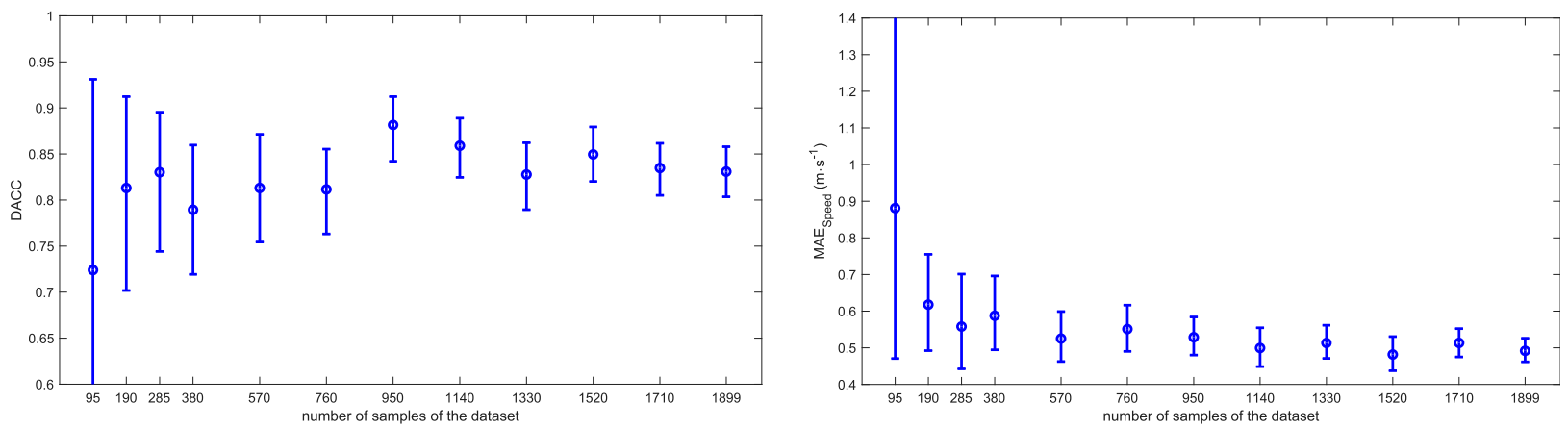

FIG. 9. Evolution of (a) DACC and (b) MAE calculated on the wind speed as a function of the size of the input dataset.

Figure 9 shows the evolution of DACC and mean absolute error for the wind speed as a function of the length of the dataset. For the longest datasets, there is no clear tendency in the evolution of performance with sample size. However, for the smallest sample sizes, the performance increases with the dataset size. Moreover, the dispersion (confidence interval), which is relatively constant beyond the 950 samples dataset, increases for the smaller sample sizes. Hence, the constant behavior of the performance metrics for datasets composed of 950-1899 samples indicates that the length of the KASCADE dataset can be considered as "long enough" to allow the ANN to sufficiently characterize the Cadarache wind patterns. The previous part demonstrated that an ANN trained with a longer dataset (e.g., the 1-yr period) neither improves the performance nor diminishes the confidence interval. From these results, we conclude that the KASCADE as well as the 1-yr-period datasets are long enough to ensure that the ANN performance is not impacted by the length of the dataset.

\section{h. Excessive nowcast of channeling}

Another limitation of the ANN is shown in Fig. 10, which exhibits the horizontal wind components' occurrence frequency. $\mathrm{ANN}_{\mathrm{K}}$ wind components (Fig. 10b) seem to be clustered in a small region of the graph, contained between the magenta lines (these have been simply hand drawn to show a visual appreciation of the larger spread of the observed data relative to the ANN data), indicating less spread wind directions than in the observations (Fig. 10a). For example, the observed east-southeasterlyto-northwesterly winds are rarely represented by the ANN (Table 4). This results in an excessive nowcast of channeled winds and a lack of cross-valley winds. We hypothesize two explanations for this behavior.
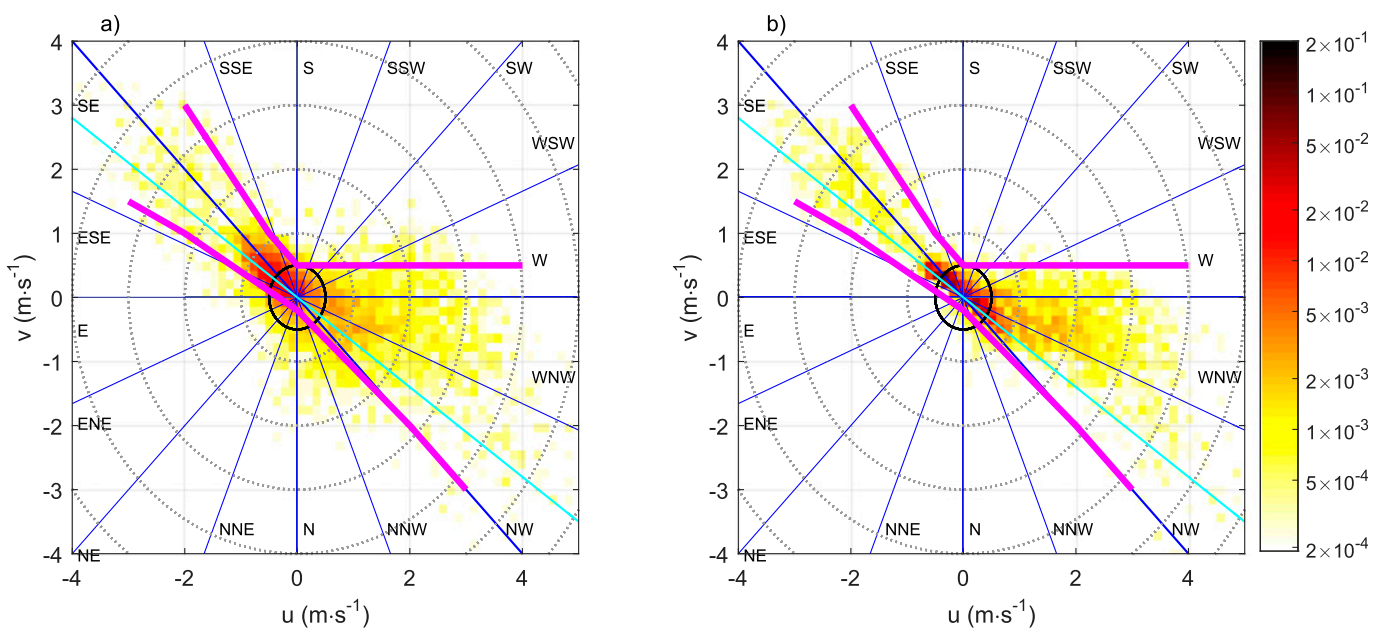

FIG. 10. Probability density of wind components at $2 \mathrm{~m}$ : (a) observed and (b) calculated by $\mathrm{ANN}_{1 \mathrm{yr}}$. The blue lines and the corresponding labels indicate the wind directions. The cyan line shows the direction of the valley axis. The dotted circles represent the wind speeds at $1 \mathrm{~m} \mathrm{~s}^{-1}$ intervals, and the solid black circle represents $0.5 \mathrm{~m} \mathrm{~s}^{-1}$. The magenta lines indicate an "envelope" that encompasses most of the ANN winds. 
TABLE 4. As in Table 2, but for the performance of $\mathrm{ANN}_{\mathrm{K}}$ when considering only observed CDV winds [ANN $\mathrm{K}_{\mathrm{K}(\mathrm{CDV})}$ ], only upvalley winds $\left[\mathrm{ANN}_{\mathrm{K}(\mathrm{CUV})}\right]$, or only cross-valley winds $\left[\mathrm{ANN}_{\mathrm{K}(\mathrm{XValley})}\right]$.

\begin{tabular}{|c|c|c|c|c|c|c|c|c|}
\hline \multirow[b]{2}{*}{ Case } & \multicolumn{3}{|c|}{ Direction indicators } & \multicolumn{3}{|c|}{ Correlation } & \multicolumn{2}{|c|}{ Speed $\left(\mathrm{m} \mathrm{s}^{-1}\right)$} \\
\hline & DACC & $\mathrm{PC} 2$ & PC4 & Speed & $u$ & $v$ & Bias & MAE \\
\hline $\mathrm{ANN}_{\mathrm{K}(\mathrm{CDV})}$ & $\begin{array}{c}0.90 \\
{[0.87,0.94]}\end{array}$ & $\begin{array}{c}0.91 \\
{[0.88,0.94]}\end{array}$ & $\begin{array}{c}0.86 \\
{[0.82,0.90]}\end{array}$ & $\begin{array}{c}0.95 \\
{[0.93,0.97]}\end{array}$ & $\begin{array}{c}0.94 \\
{[0.92,0.96]}\end{array}$ & $\begin{array}{c}0.92 \\
{[0.89,0.94]}\end{array}$ & $\begin{array}{c}-0.17 \\
{[-0.23,-0.11]}\end{array}$ & $\begin{array}{c}0.43 \\
{[0.39,0.47]}\end{array}$ \\
\hline $\mathrm{ANN}_{\mathrm{K}(\mathrm{CUV})}$ & $\begin{array}{c}0.86 \\
{[0.82,0.90]}\end{array}$ & $\begin{array}{c}0.92 \\
{[0.88,0.95]}\end{array}$ & $\begin{array}{c}0.88 \\
{[0.84,0.91]}\end{array}$ & $\begin{array}{c}0.93 \\
{[0.90,0.95]}\end{array}$ & $\begin{array}{c}0.90 \\
{[0.87,0.92]}\end{array}$ & $\begin{array}{c}0.90 \\
{[0.87,0.93]}\end{array}$ & $\begin{array}{c}-0.46 \\
{[-0.54,-0.38]}\end{array}$ & $\begin{array}{c}0.66 \\
{[0.59,0.72]}\end{array}$ \\
\hline $\mathrm{ANN}_{\mathrm{K} \text { (XValley) }}$ & $\begin{array}{c}0.38 \\
{[0.27,0.50]}\end{array}$ & $\begin{array}{c}0.65 \\
{[0.54,0.76]}\end{array}$ & $\begin{array}{c}0.52 \\
{[0.40,0.64]}\end{array}$ & $\begin{array}{c}0.77 \\
{[0.44,0.92]}\end{array}$ & $\begin{array}{c}0.86 \\
{[0.60,0.95]}\end{array}$ & $\begin{array}{c}0.31 \\
{[0.01,0.57]}\end{array}$ & $\begin{array}{c}-0.01 \\
{[-0.16,0.15]}\end{array}$ & $\begin{array}{c}0.48 \\
{[0.37,0.61]}\end{array}$ \\
\hline
\end{tabular}

First, cross-valley winds are always light, and it was shown above that these are the most challenging types of winds for the ANN to predict. Second, contrary to upand downvalley winds [section $2 \mathrm{~b}(2)$ ] there are no typical meteorological conditions associated with these winds, which therefore cannot be expressed as a mathematical relation between ANN input parameters.

This misrepresentation of cross-valley winds is visible when comparing the performances calculated on the three wind direction sectors (Table 4). The efficiency of representing cross-valley winds is much lower than for up- or downvalley winds. Indeed, performances of upand downvalley winds are higher and very close, apart from for wind speed bias and mean absolute error, explained by stronger wind speeds for upvalley winds than for downvalley winds.

Apart from the narrowness of the two main winddirection lobes in the ANN winds, the plots also reveal a nonperfect alignment between the two opposite lobes: downvalley winds are strictly parallel to the main axis of the valley, whereas upvalley directions cluster around $280^{\circ}$, that is, about a $25^{\circ}$ counterclockwise from the valley axis. This behavior, mainly observed during the day, could result from the enlargement of the valley when approaching its mouth (see Fig. 1b), and/or from downward momentum transport: above-valley winds, when they originate from the northwest quadrant, span a rather wide sector (west to northwest).

\section{Conclusions}

The goal of this study was to develop a tool for nowcasting winds in a small valley embedded in a complex topography using operational meteorological observations. In these types of situations, small-scale complex topography can give rise to local circulations, which are neither observed by routine measurements nor forecasted by operational meteorological models. The targeted area is the Cadarache valley, which is $1 \mathrm{~km}$ wide, $100 \mathrm{~m}$ deep, and $6 \mathrm{~km}$ long. At a larger scale, the wind features two main directions close to the direction of the valley axis, which is oriented $125^{\circ}-305^{\circ}$. When it is strong enough, the large-scale wind is able to force the direction of low-level winds, while a decorrelation between lowlevel winds and above-valley winds has been observed during stable conditions, producing thermally driven winds with directions forced by the topography (explaining the alignment with the valley axis). On the other hand, few observations feature light cross-valley winds which cannot be associated with any typical meteorological conditions of the region.

The ANN method was used to improve the nowcasting method of D16, which aims to assess the occurrence of thermally driven winds in the Cadarache valley, by providing both the wind speed and direction predictions. A multilayer perceptron type ANN was used to calculate the wind within the Cadarache valley using continuous observations made above the valley depth. First, the ability of the ANN was assessed by comparing its performance to the nowcasting method of D16 and to a simple MLR. The dataset used gathers observations from the 3-month-long KASCADE experiment. The ANN method produces better results than D16 and MLR methods. Furthermore, the main improvement brought by the ANN is the calculation of the wind components which allow the calculation of actual wind speeds and directions, clearly indispensable for pollutant dispersion monitoring. The method performs well: the correlation coefficients calculated for the wind components ( $u$ and $v$ ) and wind speed reach $0.95,0.93$, and 0.93 , respectively. The wind speed bias is $-0.28 \mathrm{~m} \mathrm{~s}^{-1}$ with a mean absolute error of $0.54 \mathrm{~m} \mathrm{~s}^{-1}$. Furthermore, $84 \%$ of the wind directions are correctly nowcasted within $\pm 45^{\circ}$.

This ANN uses only three variables $\left(\Delta \theta, u_{110 \mathrm{~m}}\right.$, and $v_{110 \mathrm{~m}}$ ) from the routine observations made at a height greater than the valley depth, and therefore not representative of the local flow. Despite the differences between the wind patterns at 110 and $10 \mathrm{~m}$, the wind components at $110 \mathrm{~m}$ are indispensable for the calculation of the winds at $10 \mathrm{~m}$ by the ANN. This is explained 
by a high correlation of the components between the two heights (coefficients of correlation of 0.80 and 0.81 for the $u$ and $v$ components, respectively). The difference of temperature between 110 and $2 \mathrm{~m}$ is also fundamental for the calculation of the downvalley winds under thermally stratified conditions.

However, some challenges remain, especially in the wind direction. They are explained by the method used to calculate the wind direction, which is not a direct output of the ANN. Indeed, only the wind components are calculated by the ANN, so as to avoid problems with a cyclic variable such as the direction. This introduces a limitation for the calculation of the light winds direction because a small error in the components can lead to a large error in the direction. Therefore, the ANN ability to predict wind direction improves with increasing wind speed. The other limitation encountered with the ANN method is the excessive nowcast of channeled winds, which is explained by the fact that most wind directions away from the channeled corridor correspond to very light winds whose directions are challenging for the ANN to reproduce. There is no typical meteorological situation associated with these winds. The utilization of a longer dataset, over a 1-yr period, did not fix this problem. Conversely and surprisingly, studying the impact of shorter datasets on the ANN performance proved that the length of both the KASCADE period and 1-yr-period datasets were long enough to validate the ANN calculation. Furthermore, the ANN method applied to the 1-yr period produces results that are comparable to those of the KASCADE period.

From these results, we conclude that the ANN is a suitable tool for nowcasting and downscaling winds in the Cadarache valley using routine observations. Although ANNs have already been used to nowcast meteorological variables, to the knowledge of the authors, most of these studies focused on the possibility of representing satisfactorily the wind speed but missing the wind direction. This study shows that the utilization of ANNs is a promising technique for the nowcasting of a challenging variable such as the local winds in complex topography areas based on remote measurements. We plan to apply this method to numerical mesoscale modeling outputs in order to downscale local winds in an unresolved valley.

Acknowledgments. The KASCADE field experiment was made possible by the contributions of several institutions and sources of support: CEA, Sud-PACA region, and Fulbright Scholarship Program are thanked for the financial support; Laboratoire d'Aérologie (LA, University of Toulouse) is thanked for the provision of instrumentation. LA and LMTE (CEA, Cadarache) are acknowledged for their participation in the field campaign, which was hosted by LMTE. The SEDOO, Observatoire Midi-Pyrénées, is acknowledged for its help in database management. We thank the reviewers for their constructive feedback on the manuscript.

\section{REFERENCES}

Bastin, S., P. Drobinski, A. Dabas, P. Delville, O. Reitebuch, and C. Werner, 2005: Impact of the Rhône and Durance valleys on sea-breeze circulation in the Marseille area. Atmos. Res., 74, 303-328, https://doi.org/10.1016/j.atmosres.2004.04.014.

Beale, M., M. T. Hagan, and H. B. Demuth, 2010: Neural network toolbox 7: User's guide. MathWorks, $951 \mathrm{pp}$.

Berthou, S., and Coauthors, 2016: Influence of submonthly air-sea coupling on heavy precipitation events in the western Mediterranean basin. Quart. J. Roy. Meteor. Soc., 142, 453-471, https://doi.org/10.1002/qj.2717.

Burns, P., and C. Chemel, 2015: Interactions between downslope flows and a developing cold-air pool. Bound-Layer Meteor., 154, 57-80, https://doi.org/10.1007/s10546-014-9958-7.

Cadenas, E., and W. Rivera, 2009: Short term wind speed forecasting in la Venta, Oaxaca, México, using artificial neural networks. Renewable Energy, 34, 274-278, https://doi.org/10.1016/ j.renene.2008.03.014.

Chow, F. K., S. F. De Wekker, and B. J. Snyder, 2012: Mountain Weather Research and Forecasting: Recent Progress and Current Challenges. Springer Science \& Business Media, 750 pp.

Clements, C. B., C. D. Whiteman, and J. D. Horel, 2003: Cold-airpool structure and evolution in a mountain basin: Peter Sinks, Utah. J. Appl. Meteor., 42, 752-768, https://doi.org/10.1175/ 1520-0450(2003)042<0752:CSAEIA $>2.0$.CO;2.

Clements, W. E., J. A. Archuleta, and P. H. Gudiksen, 1989: Experimental design of the 1984 ascot field study. J. Appl. Meteor., 28, 405-413, https://doi.org/10.1175/1520-0450(1989) $028<0405$ :EDOTAF $>2.0$. CO;2.

Delon, C., D. Serça, C. Boissard, R. Dupont, A. Dutot, P. Laville, P. De Rosnay, and R. Delmas, 2007: Soil no emissions modelling using artificial neural network. Tellus, 59B, 502-513, https://doi.org/10.1111/j.1600-0889.2007.00254.x.

Doran, J., J. D. Fast, and J. Horel, 2002: The VTMX 2000 campaign. Bull. Amer. Meteor. Soc., 83, 537-551, https://doi.org/ 10.1175/1520-0477(2002)083<0537:TVC >2.3.CO;2.

Dreyfus, G., J. Martinez, M. Samuelides, M. B. Gordon, F. Badran, S. Thiria, and L. Herault, 2002: Réseaux de Neurones: Méthodologie et Applications. Eyrolles, 408 pp.

Duine, G.-J., T. Hedde, P. Roubin, and P. Durand, 2016: A simple method based on routine observations to nowcast down-valley flows in shallow, narrow valleys. J. Appl. Meteor. Climatol., 55, 1497-1511, https://doi.org/10.1175/JAMC-D-15-0274.1.

$-,-\longrightarrow,-$ M. Lothon, F. Lohou, P. Augustin, and M. Fourmentin, 2017: Characterization of valley flows within two confluent valleys under stable conditions: Observations from the KASCADE field experiment. Quart. J. Roy. Meteor. Soc., 143, 1886-1902, https://doi.org/10.1002/qj.3049.

Fernando, H., and Coauthors, 2015: The Materhorn: Unraveling the intricacies of mountain weather. Bull. Amer. Meteor. Soc., 96, 1945-1967, https://doi.org/10.1175/BAMS-D-13-00131.1.

Gardner, M. W., and S. Dorling, 1998: Artificial neural networks (the multilayer perceptron)-A review of applications in the 
atmospheric sciences. Atmos. Environ., 32, 2627-2636, https:// doi.org/10.1016/S1352-2310(97)00447-0.

Khosravi, A., R. Koury, L. Machado, and J. Pabon, 2018: Prediction of wind speed and wind direction using artificial neural network, support vector regression and adaptive neuro-fuzzy inference system. Sustainable Energy Technol. Assess., 25, 146-160, https://doi.org/10.1016/j.seta.2018.01.001.

Lareau, N. P., E. Crosman, C. D. Whiteman, J. D. Horel, S. W. Hoch, W. O. Brown, and T. W. Horst, 2013: The persistent cold-air pool study. Bull. Amer. Meteor. Soc., 94, 51-63, https://doi.org/ 10.1175/BAMS-D-11-00255.1.

More, A., and M. Deo, 2003: Forecasting wind with neural networks. Mar. Structures, 16, 35-49, https://doi.org/10.1016/ S0951-8339(02)00053-9.

Muñoz, R. C., M. J. Falvey, M. Araya, and M. Jacques-Coper, 2013: Strong down-valley low-level jets over the Atacama Desert: Observational characterization. J. Appl. Meteor. Climatol., 52, 2735-2752, https://doi.org/10.1175/JAMC-D13-063.1.

Philippopoulos, K., and D. Deligiorgi, 2012: Application of artificial neural networks for the spatial estimation of wind speed in a coastal region with complex topography. Renewable Energy, 38, 75-82, https://doi.org/10.1016/j.renene.2011.07.007.

Price, J., and Coauthors, 2011: COLPEX: Field and numerical studies over a region of small hills. Bull. Amer. Meteor. Soc., 92, 1636-1650, https://doi.org/10.1175/2011BAMS3032.1.
Rotach, M. W., and Coauthors, 2017: Investigating exchange processes over complex topography: The Innsbruck Box (i-Box). Bull. Amer. Meteor. Soc., 98, 787-805, https://doi.org/10.1175/ BAMS-D-15-00246.1.

Sabatier, T., A. Paci, G. Canut, Y. Largeron, A. Dabas, J.-M. Donier, and T. Douffet, 2018: Wintertime local wind dynamics from scanning Doppler lidar and air quality in the Arve River valley. Atmosphere, 9, 118, https://doi.org/10.3390/ atmos 9040118.

Santos-Alamillos, F., D. Pozo-Vázquez, J. Ruiz-Arias, V. LaraFanego, and J. Tovar-Pescador, 2013: Analysis of WRF Model wind estimate sensitivity to physics parameterization choice and terrain representation in Andalusia (southern Spain). J. Appl. Meteor. Climatol., 52, 1592-1609, https://doi.org/ 10.1175/JAMC-D-12-0204.1.

Simpson, J. E., 1994: Sea Breeze and Local Winds. Cambridge University Press, 252 pp.

Whiteman, C. D., and J. C. Doran, 1993: The relationship between overlying synoptic-scale flows and winds within a valley. J. Appl. Meteor., 32, 1669-1682, https://doi.org/10.1175/ 1520-0450(1993)032<1669:TRBOSS > 2.0.CO;2.

—, and Coauthors, 2008: METCRAX 2006: Meteorological experiments in Arizona's meteor crater. Bull. Amer. Meteor. Soc, 89, 1665-1680, https://doi.org/10.1175/2008BAMS2574.1.

Yegnanarayana, B., 2009: Artificial Neural Networks. PHI Learning Pvt. Ltd., 476 pp. 